\title{
Communicating Veganism: Evolving Theoretical Challenges to Mainstreaming Ideas
}

\author{
Noah J. Wescombe \\ Correspondence: Noah J. Wescombe, School for Policy Studies, University of Bristol, United Kingdom.
}

Received: May 17, 2019

doi:10.11114/smc.v7i2.4367

\author{
Accepted: July 3, 2019 \\ Online Published: July 4, 2019 \\ URL: https://doi.org/10.11114/smc.v7i2.4367
}

\begin{abstract}
Veganism, as both a philosophy and social movement, faces numerous challenges to the communication of its ideas across society. As a unique modern counterculture, it stands in contravention of prevailing anthropological discourses that dominate conceptual frameworks. This has led to difficulty in constructing updated virtue epistemologies that result in veganism as a logical moral conclusion. It is clear that new social discourses need developing, and that this is a primary concern for affirming moral agency. To explain this and identify key issues and features, vegan communications are evaluated herein from a philosophical, psychological, and informational perspective, with a view of both historical and modern social contexts. In doing so, a number of novel theoretical reflections are offered. This is done through a discussion separated into four sections dealing first with a view of veganism in evolution, secondly with the social complexity of media trends and social positioning, thirdly with achieving constructive dialogue given present-day challenges, and finally with a discussion of modern information systems. Overall, this broad systems view of veganism in society leads to the conclusion that an up-to-date vegan communication theory must necessarily incorporate such diversity considerations, and must also generate a new discourse that is in line with the complex nature of social dynamics and individual development. Done prudently, this could propel vegan ideas further into the mainstream of conversation and consciousness, fostering a new paradigm for consumption.
\end{abstract}

Keywords: veganism, information, communication, social systems, ethics, social positioning

\section{Introduction}

Only a few decades ago, the word "vegan" might have been viewed as ambiguous, with some confusion over its meaning as well as antipathy to its implications. This may still be the case, with such prevailing semantic symbolism being perhaps reflective of its marginality and social rejection. However, as ideas have evolved, veganism has arguably become something of a unique counterculture - a taboo of conversation - but one which is becoming increasingly prolific in the mainstream culture of developed nations. Information flows from varieties of media facilitate recurring exposure to both vegan cooking, health, and lifestyle, as well as (though less so) the realities of how animals are treated (GlobalData, 2017). With such attention, proportional social tensions are expected. The philosophy of veganism has therefore become more prominent in the public consciousness in recent times. Core tenets include deep ethical epistemologies that reach to the very heart of modern society, offering a critical perspective to the unacknowledged and marginalised issues of animal lives. However, the vegan movement, as will be demonstrated herein, suffers from obstacles to the successful communication of its ideas; for reasons linked both to its current social positioning, and informational challenges linked to its breath as a philosophy. Disputes also arise over the existence of "isms" themselves, and whether or not they are conducive to meaningful agency at the societal level, given the tendency of ideologies to divide rather than unite.

This paper will build on the existing literature of vegan communications, as well as modern theoretical media studies, by identifying and examining how the key themes of difficulty - philosophical, psychological, and informational are continually evolving with the times, and how they link into complex social dynamics. Such an evaluation is relevant and important from a theoretical perspective, as it seeks to encourage an approach to discourses around veganism that acknowledge its true conceptual form, as a multifaceted philosophy in transition. Only by managing expectations of individual moral agents in society can ideas be appropriately introduced and shared; thereby fostering sufficient virtue epistemologies for the widespread application of vegan ethics across modern society — or at the very least, increased understanding of them - for enhanced moral agency. 


\section{Veganism in Evolution}

Philosophically, many of the precepts of veganism are not modern in their genesis. Jainism and Buddhism advocated non-violence to animals from the 6th Century BCE (Spencer, 1993). However, what is now - and has been since the mid 20th Century (Watson, 1944) - known as veganism differs in a number of important respects from the ancient derivations. What began as a systems perspective for morality driven by holistic spiritualisms has evolved into an applied ethical discourse within which such spirituality is now a sufficient, but no longer necessary, condition for its adherence. This has changed its nature: from a culturally embedded ontology of being, to what can be described as a moral realism. What is meant by this is that there has essentially been a flipping of the philosophical nature of animal non-exploitation: today's materialism concerns itself with the realities of pain, justifying its stance based on emotive grounds; a response to suffering experienced in the world. One of the foremost thinkers to drive this modern evolution was Peter Singer, who challenged fundamental justifications for levels of suffering based on a status of being: first through preference utilitarianism (1979), and then later through hedonistic utilitarianism (2014). While the Ancients practiced what could be referred to as a flat, egalitarian correspondence of being, which prevented power relations leading to animal exploitation by humans, the modern approach is not grounded in such a recognition and even garners it irrelevant. In other words, the animal rights movement, from a Singerian viewpoint, is moderate in its judgement of human-animal relations: non-human animals are still inferior, but by utilitarian means, the rational human can judge that it is wrong to kill them for insufficient reasons. This is highly significant to recognise when considering the dynamics of social ethics, and can be incorporated into a deep historical approach to the sociology, politics, and economics of humanism. As such, veganism as a philosophy necessarily has a great deal to say about all three of these areas, but does so in counterposition to anthropological history concerning natural norms.

Looking back on human history, one need not look far to see the realities of human need predefining the nature of human-animal relations. Meat, in particular, has been a commodity since the dawn of mankind, given its caloric and nutrient density. It is instinctual to be drawn, psychobiologically, to food sources that are most economically viable, and this is referring to "economic" in an entirely holistic and fundamental sense of time/energy to reward ratios. If an animal was available to hunt, it made sense to pursue it, for the rewards were large in convenience value relative to the caloric and nutrient value. Indeed, it is by no means trivial that, throughout our history, humankind has communicated around meat and animal handling, as well as concerning the other useful byproducts animal bodies provide. This can be interpreted beyond a mere basic preference interest (Singer, 1979) as an anthropological discourse, which has ongoing sociocultural influences for production and consumption. Such a dialogue maintains carnism as a core aspect to human society, making any direct counterposition difficult to incorporate into being. Carnism, to offer succinct definition, is the prevailing ideology of mankind in which people support the use and consumption of meat and other animal products (Joy, 2003). As such it is the direct opposite of veganism. Appreciating the strong origins of carnism as an anthropological phenomenon is key to the positioning of an evolving paradigm of conception for human-animal relations, but more importantly for communicating across ideologies (Freeman, 2016). This brings preference utilitarianism into social, political, and economic consideration: social demand for freedom of choice is supported by political apparatus (at least in the West), which in turn is concerned with legally maintaining the manifestation of preference utilitarianism in the free market. Singer, though critical of capitalism for its game-theoretic faults, recognises that an evolution of natural morality, via a kind of Darwinian process of social-biological networking (2000), is manifested in well-functioning free markets by the very nature of cooperation and economic exchange. From a natural law perspective then, it is logically consistent that an evolution of moral principles must be propelled by movements in the social realm, which then become political and economic changes via changes to preference. This notion is integral to a complex-social systems approach to ethical development in society, leading to emergent effects elsewhere. Such potentiality is only possible thanks to human economic and social development, where plant agriculture can fully satisfy all the nutritional needs of human beings. Indeed, development discourses are something everyone can reasonably and intuitively support. Nonetheless, carnism remains dominant as an anthropological discourse, showing that our preference roots are strong enough to corrupt moral judgement, systemically leading to a failure of preference utilitarianism. Communicating ideas therefore becomes an essential condition for human social-ethical progress, but must be appropriate for the current state of veganism as a philosophy-in-transition, and the informational modes of modern society.

\section{Media Trends and Sociocultural Positioning}

Much of the modern-day exposure to vegan lifestyles come from current forms of media: social media, magazines, and newspapers; likely in that order, given the hierarchy of popularity/readership for each. The countercultural aspect to veganism, as outlined previously, has created a certain degree of "trendiness" to the vegan movement. Theoretically, for communication, this has its benefits and drawbacks. On the one hand, increased likelihood of the media giving vegan ideas attention, particularly centred on food choices, improves exposure. If eating a certain way, and being 
conscientious of food origins, becomes trendy, then more people are likely to try it and be open to it; thus dissolving the cultural taboo. Such a process can be seen as one dimension of social-ethical evolution. However, it can be debated as to what constitutes "vegan" ideas as explored, shared, or presented in media, or whether its trendiness is sourced from other social values. A prominent example can be seen in the Avocado craze of 2017, when the price of avocados skyrocketed in response to extreme rises in demand by consumers in the USA, Europe, and China (Schwartz, 2017). Classed as something of a social media fad for "Instagrammable" plant-based and "superfood" dishes, this trend can be seen as linked to the rising plant-based eating movement as a consumer trend (Bellemare and Fajardo-Gonzales, 2018), but with no perceivable relation to the basis of vegan ethics. Rather, aesthetics of lifestyle and following of social trends encourage superficial engagement with specific food stuffs, dishes, and products that rise to favoured social framing, particularly for the young (Roberts, Yaya, and Manolis, 2014). Case-in-point, economic and environmental concerns as to the excessive production and export of Avocados and Quinoa — primarily from Mexico and Latin America presented further non-correlation to moral ideas.

These kinds of phenomena are explainable through a recognition that, psychologically, day-to-day experience and conception of ideas is dominated by a preference for symbols of comfort, pleasure, and happiness. This intends to enrich everyday experience of life with common appreciated aesthetics, much like an opiate. Thus it is no surprise that mild addictions to such media are becoming commonplace, with the continual perceptual rewards of such recently being incorporated into Learning Theory of addiction aetiology (Chakraborty, Basu and Kumar, 2010). Though it is a popular mantra that "bad news sells" in journalism, the same is not the case for the lifestyle and social media channels, which have a unique aesthetic to them by fundamental design. The process of attaining animal products in the animal agriculture industry (the critical core of the vegan movement) is rarely covered, with focus on economic, environmental, and health aspects being judged more socially appropriate and of greater interest to readers in recent times (Willet et al. 2019). This is interesting from a theory of media perspective, given that these issues are still emotive, and in conventional media forms still depend on a journalistic craft that draws on pathos and psychologies of guilt. (Höijer, 2010). It appears that there is a limit associated with acceptable framing of issues, influenced by cultural/political agendas. In basic terms, too extreme an informational exposure to mass killing can cause backlash, which could arguably be mapped onto the Kübler-Ross model of psycho-cognitive processing (Cushing, 2019). The crux of the problem is that this is arguably the main argument for veganism itself: the narrative on the reality of the sheer amount of death, in the tens of billions annually (FAO, 2018). This may result in excessive information for individual media consumers - and indeed outlets, behind which are ultimately also humans — to handle epistemically, thus cognitive and emotional defences are raised in the classical forms of denial (Cohen, 2001). The systemic tragedy may be judged as morally repugnant, but it is also beyond their direct reach. In turn, this justifies a separation from the issues, whereby the problems are seen as too large for individual action to make enough of a difference to justify a substantial alteration of their preferences.

Such an evaluative procedure ties back into the utilitarianism of Singer, where recognition of universal preferences, and hedonistic concerns at a systems level, comprise the required epistemology for moral agency. This approach fails in the present day precisely because the approach requires something beyond the social conditions under which one lives. Herein lies a conceptual problem with veganism in its 20th-21st Century form: its ethical demands require an engagement with conceptions of scale and systems conditions that seem abstract from the perspective of the individual. In this sense, and in the context of an evolving veganism, a return to spiritualised foundations for the precepts of veganism actually becomes more individually useful than a moral realism, based in preference or hedonistic utilitarian bases. Regardless, this is not where the evolution of veganism has arrived at to date, even if Buddhist or Pantheist leanings are highly probable and compatible corollaries to veganism (McPhereson, 2018). Any perceived identity-political, or lifestyle-political (Bennett, 2004) dimension detrimentally impacts the interest in, and appetite for, vegan lifestyles, due to associated values attached to a general identity assumption. "Vegan" as a label can also be said to contribute to this, insofar as it becomes a branded term signifying a strong political stance. This problem can be framed as epistemic injustice (Fricker, 2007), where the social positioning becomes so entwined with a conceptual framework that dialogue becomes mired in distraction: a focus on the basic framing rather than the deep ideas themselves. Ad hominem tendencies are native to such issues arising in argumentation. The gendered dimension to veganism is a prime example of this in reality, which presents a unique obstacle of sociocultural positioning. The narrative of meat-and-masculinity appear to be archaic, with associations of manliness being linked to predatory, hunter-like traits which correspond to strength, speed, and competence, even if this has no bearing whatsoever on the present day. Such a phenomenon might be categorised psychoanalytically as "revelling in the abstraction of killing", connecting the consumer to a more primal nature. Virtuous behaviour is positioned as more feminine, such that veganism is cast as "soft" relative to omnivorous consumption (Ruby and Heine, 2011). Again, this is an example of the prevailing anthropological discourse, backed by a conceptual framework rooted in the natural realm, manifesting itself in socio-biological identity. Indeed, recent data gives that the majority of vegans are female 'e.g. $74 \%$ in USA, $66 \%$ in 
Germany and 63\% in UK' (Martinelli and Berkmanienè, 2018). The fact that this is the case is cause for great concern: if the virtues of veganism remain mired in such an identity framework, demographics (in the form of socially positioned identity groupings) present a major barrier to communication. "Mainstreaming" the philosophy is the only option for overcoming this, and increasing the openness to vegan ideas and options for individual preference change. The mainstream is the most politically and culturally neutral positioning by definition, meaning that it does not correspond to such epistemic injustice.

\section{Mainstreaming Constructive Dialogue}

A number of interactive problems stand in the way of communications that might shift society toward a more vegan-friendly paradigm, such that the relevant philosophical ideas and debates might become mainstream. It is important to note that, in the conception of "mainstream", there is a context of interplaying factors such as personal social networks and conditions; basic details such as the degree of minority of vegan views in friend and family circles. Another factor is an inertial aspect to the discourse regarding a requirement of holistic justification on the part of the vegan, as the extreme minority view. For the advocate, this results in an increasingly high burden of proof in communication of ideas. A particularly notable difficulty arises surrounding the relevant health debate, with the discourse reaching awkward depths that are exclusive from the rhetorical abilities of the advocate. The reasoning runs as follows: the advocate attempts to connect the subject with the moral nature of animal exploitation. In response, the subject counters with the view that animal consumption is nutritionally necessary. Irrespective of the subject's knowledge of the biomedical literature, the burden is on the advocate to present the facts in not only a sufficient manner, but also coherently to convince the subject. For this to be successful, conditions such as time, mutual engagement and commitment to the discussion, patience, and respect, must be met (to a degree that varies by subject temperament). In the biomedical context, trust is highly valued in society, so there are inevitable limits to persuasion, again depending on the subject's temperament. There is therefore no guarantee that a biomedical or nutritional discussion brings about constructive dialogue; issues of trust and incomplete information and understanding of details can present a serious challenge to the advocate. This has feedback loops to the aforementioned delicate criteria of time, commitment, patience, and respect, where these are at higher risk of disruption as complexities and stalemates mount. This is not to suggest that all communications are adversarial in nature, and therefore develop in manners that raise tensions and decrease the marginal utility of interaction from both sides of the dialogue. Rather, it is important to note that the opportunities for connection to the facts of the matter vary with the competence of both parties, as well as the noted criteria.

In this context, it can be argued that cognitive dissonance, a popular concept in modern vegan advocacy, is particularly relevant to communication challenges. This is a justifiable claim considering informational dimensions to sociocultural discourse, and prevailing dominant paradigms. Festinger (1957) claims that when individuals hold two or more cognitions that are contradictory, they will feel an unpleasant state - dissonance — until they are able to resolve this state by altering their cognitions. Indeed, it could be hypothesised that the rise of non-violence culture, in the forms of veganism and environmentalism, through the 1960s and 70s, was linked to the correlated rise in social and psychological research at that time (Shiraev, 2010). This is a matter for a separate piece of analysis. In any case, the issue of conflicting narratives on human systems, and their relations to the rest of the natural world, is a likely point of origin for cognitive dissonance. Indeed, it has been proposed by behavioural economists that the internal dialogues that constitute such dissonance can dramatically influence economic agency, even if the underlying volition runs counter to their interests (Akerlof and Dickens, 1982). This theory emphasises the importance of sociocultural paradigms, such as carnism, and their influence upon preferences. In turn, dominant ideas define the receptiveness of subjects to ideas that require a definitive change in philosophy and agency, often running contrary to societal norms. Even with a recognition of guilt, there is a strong system-framework to fall back on, constructed by the vast majority of similarly situated conceivers, that epistemically maintains the parameters and limits the need for change.

You may feel you're under a moral obligation to change once you know that an ethical (as opposed to juridical) crime of unimaginable proportions is being committed every day and everywhere in the industrialized West, but it's also the case that such knowledge doesn't in fact oblige you in any straightforward sense to change. (Salih, 2014)

This ties back into the idea of veganism as a philosophy in transition, where societal forces combine with the power of vegan moral precepts to shape its growth and uptake in a complex-systems manner. Obstacles to communication arise where conceptualisations are out of sync with the informationally mainstream in society, wherein knowledge barriers reduce receptivity and susceptivity to new concepts. This is certainly still very much the case with veganism: the public exposure to vegan ideas is still stigmatised as extreme, grandstanding, or merely foolish and pointless (Cole and Morgan, 2011). Resultantly, there is a reluctance to engage in the relevant substantive issues. Therefore it logically follows that a cumulative approach to social information theory needs to be incorporated with psychological 
considerations, to build up familiarity toward a mainstreaming of such concepts. These includes the reframing of vegan ideas as not generally antithetical, but rather a familiar and well-intended option for individuals in society.

This is no easy task, as it runs contrary to the "killjoy" theory of ideological contrarianism (Ahmed, 2010) which, applied to veganism, presents the idea-contention and language-paradigm as detrimental to the comfort and pleasure of carnist activities, causing division and consolidating vegans as a minority. This can be mapped onto micro-social situations in the family, friends, and colleagues, such that killjoy status becomes affirmed interpersonally. How these situations are managed has a major impact on how aforementioned conceptual associations may be drawn up by non-vegans. It also strongly influences the quality of experience for the vegan, which directly influence feelings of alienation or being misunderstood. Given that familial social ties are most resilient to ideological tensions, by the nature of their strength and general lack of relationship conditionality, the family dinner table need not be a place of discord. Rather, there is valuable opportunity for constructive outcomes. Twine (2014) in the context of killjoys, identifies the significance of "non-vegan vegan advocates" who inadvertently promote the practice by virtue of their familiarity thanks to their close friends and relatives, who also have the base advantage of being favoured by the respective non-vegan. Twine's interview findings show that 'as a demonstration of care friends and family members will often start to perform certain aspects of vegan practice.' Such a phenomena is key to the mainstreaming of vegan ideas, where behaviour tends toward, or is at least open to, principles of veganism. This a gradualist approach, which emphasises individual agency as an outcome of close social-informational networks, can be seen to rid veganism of its political and contrarian nature, allowing its transition to another part of everyday life. The ideas themselves are thus encountered by non-vegans more neutrally, on their own terms, reducing hostility and othering.

\section{The Role of Information Systems}

Modern information and communication systems create the opportunity for technical leveraging of discourse in a manner that was simply impossible prior to technological advancement. Interconnectivity and globalisation of information flows has made it possible to accumulate knowledge and therefore combat anthropological discourses in the aforementioned manner. Simultaneously, the requirement for individual change is as strong as ever, leaving the battle of inner cognitive dimensions to be fought at the level of the independent subjects who constitute society. In this sense, the revolution of consumer preference is informational in the first order, and economic in the second order: both require consumption in order to manifest change objectively. Counterintuitively however, the order can also be reverse-circulated. Such a theoretical insight is supported by informatic features such as content algorithms utilised by social media and news media, which self-define service architecture of information systems based on data feedback loops (Steiner, 2012). The information exposure is therefore reflective of existing preferences. At a higher level of evaluation, this could be seen as the most fundamental characteristic of modern information systems: a product of cybernetic transference that dictates probability of information exposure. Epistemic injustice has already been mentioned in Section 2, but the resulting variation in preferences that are leveraged by algorithmic intelligence specifically results in hermeneutical injustices (Fricker, 2007). Predictive informatics can serve to maintain the conceptual status quo of individuals, who are consuming a market service (which is necessarily based on personal preferences). Again, the multidisciplinary nature of the modern vegan position presents multiple opportunities for these systems to exacerbate problems, due to the multiplicity of conceptual positions and interpretive approaches to science. The health debate suffers most from this, though matters of environmental economics also hold risk. Such branching discourses provide difficulty for moving forward in breaking down existing hermeneutic paradigms and introducing truths.

Even so, the paradox is that modern information technologies are most consumed by those that are the most likely to be open and receptive to vegan communications. According to polling from The Guardian newspaper, more than four in ten UK vegans are Millennials (between 15 and 35 years old), and the trend culture - previously mentioned in Section 2 - is a large part of their social identity (27th May, 2016). Though this identity can be viewed as superficial by its materialist phenomenology and social-networked nature, the increased receptivity to a new cultural paradigm of consumerism should not be underestimated. It is this very process that drives a gradual process of systems change in the free market of goods and services, allowing for conceptual frameworks to strengthen over time. The sheer amount of data that consumers are exposed to, and contribute in turn, is auto-cycling a constructive process for social learning, with heavy emphasis on a observational learning component (Bandura, 1977). Placing social consciousness in a cybernetic dimension can serve as greatly relevant for considering how socio-informational positioning occurs in these spaces, and how they differ from social positioning in other media dimensions. If the logics of these systems result in particularly engineered parameters for information exposure, the communication of ideas suffer from both conventional institutional dynamics as well as novel ones from algorithmic operations (Klinger and Svensson, 2018). Given this, the emergent effects of this complex interaction of conventional media content design, and algorithmic information processing, can be seen as a combination of intended targeting and predictive targeting. Explaining this more clearly, it is theoretically well-understood that institutionalised interests dominate conventional news media and journalism, 
(Callaghan and Schnell, 2010) such that the information system is internally biased. Algorithmic processing, rather, introduces a different form of institutionalisation, from the technology network respectively, and is a matter of external bias. Design of these data-driven processes are the subject of much current controversy and debate, where results reflect implicit biases toward certain data. Given that modern information technology platforms for media are a combination of both third party media outlets and data engineering presents a new challenge to conventional theoretical understandings of media, and communications in general.

How consumers are exposed to information is down to the complex interaction between these internal and external biases, blurring the previously clear lines between party interests and content placement. For the publication and dissemination of vegan ideas, there is a high risk of, and vulnerability to, siloing network effects that concentrate in areas of high declared interest (such as is the case with Facebook Feed algorithms for example) (Napoli, 2014). The commercialisation of media content online has arguably led to a "click-culture", where third party outlets will purposefully present information of interest to specifically targeted user groups (categorised by declared preferences in the form of "thick data") (Langlois and Elmer, 2013). Additionally, the fundamental principles of veganism concern, foremost, the systemic mass killing of animals, such that much of the narrative communicated in media makes use of gore and violence. While this is explicit in nature and meant to induce emotional reactions from subjects, this may exacerbate the limits to appearances on the feeds of users who have contrasting preferences. Not only does the behaviour of such so-called "information" system limit the public discourse, but it also contributes to the maintenance of cognitive dissonance, essentially re-networking ethical divisions cybernetically. Other related discourses that correspond to universalised ethics such as environmentalism and human rights causes do not suffer from this, so can be judged, at least theoretically, to have greater compatibility with the nature and functionality of these systems. Indeed, while the vegan activism that propels much of the relevant social media content is focused on animal rights and the shock-factor, combining veganism with these extant, successful discourses may help to slipstream ideas to a broader audience. The advantage of this is also that it lowers the threshold for acceptance, connecting ethical decisions in one domain (animal welfare) to such notions as environmental sustainability (Pendergrast, 2016). Framing information in this way can generate increased paths to virtuous action without the more controversial foundational principles. If this is iterated over enough people, positive change could be achieved to a greater degree than if vegans retain more heavy-handed, purist approaches to information distribution.

\section{Conclusion: An Evolving Paradigm}

Drawing on the many points noted herein, it is clear that an optimal, up-to-date approach to communicating veganism is one that considers, holistically, a wide range of philosophical, psychological, and informational features to today's society. In the interest of doing justice to the movement, and then ultimately for universal notions of optimal welfare, we must reconsider our approaches. If veganism is to be taken seriously as not only a cultural phenomenon, but also as an encompassing ethical movement, boundaries must be broken down, and mutual understandings fostered irrespective of individual background. What can be seen from discussion is that the communication of veganism is essentially a project of virtue epistemology: one that uses the tools of human psychology and cognition to ground an applied ethic in truths about the extreme exploitation of animals today, and what one should do about it. Over time, it is theoretically reasonable to expect a convergence of the social with the economic, due to virtue epistemologies constructed through these means, leading to increased uptake of vegan-friendly economic consumption.

There is a long and hard journey ahead for veganism. Given that food, in particular, is one of the most fundamental of human markets - and, as has been identified, is influenced by deep and complex social positioning — change here requires a gradual alteration of acceptable parameters for products, stimulated by free choice, so as not to cause social discontentment and cultural upheaval. This is a core feature of a systems approach to free markets that incorporates sociological and behavioural theory to bring economic activity into correlation with newly enriched social-individual features (Wescombe, 2019). Though veganism has its urgentist policy proponents, who are propelled by disgust and a moral panic over the current system of animal agriculture, the philosophy as a whole is not at all totalitarian in its modern presentation. The exercising of individual rationality, in response to relevant information, is what the vegan movement puts its faith in and contributes the majority of its time toward. It is the outcome of this that is the most viable virtue epistemology to be generated - that which comes directly from the awareness and judgement of the informed individual. The extents of ideologies is therefore of significance in balancing virtuous principles with social phenomena. Taken too far into radicalism, due to a passionate expression of convictions, veganism can suffer greatly, proportional to its current state of vulnerability as a minority viewpoint and culturally unaccepted ideology. If prudence is taken however, there is opportunity to rise beyond "isms" and carnist-vegan dilemmas, toward constructive information sharing and open dialogue in mainstream culture. In the modern context of the way information is distributed and interfaced with, such a theoretical approach is necessary to overcome corresponding hurdles and build meaningful conversation. 


\section{References}

Ahmed, S. (2010). Feminist Killjoys (And Other Willful Subjects). https://doi.org/10.1215/9780822392781-003

Akerlof, G., \& Dickens, W. (1982). The Economic Consequences of Cognitive Dissonance. The American Economic Review, 72(3), 307-319. Retrieved from http://www.jstor.org/stable/1831534

Bandura, A. (1977). Self-efficacy: Toward a Unified Theory of Behavioural Change, Psychological Review, 84(2). https://doi.org/10.1037//0033-295X.84.2.191

Bellemare, M. F., Fajardo-Gonzalez, J., \& Gitter, S. R. (2018). Foods and fads: The welfare impacts of rising quinoa prices in Peru, World Development, 112. https://doi.org/10.1016/j.worlddev.2018.07.012

Bennett, W. L. (2004). Branded Political Communications, Lifestyle Politics, Logo Campaigns, and the Rise of Global Citizenship, in Micheletti, M., Follesdal, A., Stolle, D., (Eds.), Politics, Products, and Markets: Exploring Political Consumerism Past and Present, 101-125, Transaction Publishers. https://doi.org/10.4324/9781315126937-7

Callaghan, K., \& Schnell, F. (2001). Assessing the Democratic Debate: How the News Media Frame Elite Policy Discourse, Political Communication, 18(2), 183-213. https://doi.org/10.1080/105846001750322970

Chakraborty, K., Basu, D., \& Kumar, K. G. V. (2010). Internet addiction: Consensus, controversies, and the way ahead. East Asian Arch Psychiatry, 20, 123-132.

Cohen, S. (2001). States of Denial: Knowing about Atrocities and Suffering, Blackwell Publishing.

Cole, M., \& Morgan, K. (2011). Vegaphobia: derogatory discourses of veganism and the reproduction of speciesism in UK national newspapers 1. The British Journal of Sociology, 62(1), 134-153. https://doi.org/10.1111/j.1468-4446.2010.01348.x

Cushing, N. (2019). To Eat or Not to Eat Kangaroo: Bargaining over Food Choice in the Anthropocene, Journal of Media and Culture, 22(2). Available from:

http://www.journal.media-culture.org.au/index.php/mcjournal/article/view/1508

FAO (2018). Animal Agriculture Statistics. http://www.fao.org/faostat/en/\#data/QL

Festinger, L. (1957). A Theory of Cognitive Dissonance. California: Stanford University Press.

Freeman, C. P. (2014). Chapter 2: Ethical Views on Animals as Fellows and as Food. In Framing Farming. Leiden, The Netherlands: Brill | Rodopi. https://doi.org/10.1163/9789401211741_003

Fricker, M. (2007). Hermeneutical Injustice. In (Ed.), Epistemic Injustice: Power and the Ethics of Knowing, Oxford University Press. Available from https://doi.org/10.1093/acprof:oso/9780198237907.003.0008

GlobalData (2017). Top Trends in Prepared Foods 2017: Exploring trends in meat, fish and seafood; pasta, noodles and rice; prepared meals; savory deli food; soup; and meat substitutes. Available from: https://www.reportbuyer.com/product/4959853/top-trends-in-prepared-foods-2017-exploring-trends-in-meat-fish-a nd-seafood-pasta-noodles-and-rice-prepared-meals-savory-deli-food-soup-and-meat-substitutes.html

Höijer, B. (2010). Emotional anchoring and objectification in the media reporting on climate change. Public Understanding of Science, 19(6), 717-731. https://doi.org/10.1177/0963662509348863

Joy, M. (2003). Why We Love Dogs, Eat Pigs, and Wear Cows: An Introduction to Carnism, Conari Press.

Klinger, U., \& Svensson, J. (2018). The end of media logics? On algorithms and agency. New Media \& Society, 20(12), 4653-4670. https://doi.org/10.1177/1461444818779750

Langlois, G., \& Elmer, G. (2013). The research politics of social media platforms. Culture Machine, $14,1-17$. Available at: https://www.culturemachine.net/index.php/cm/article/viewArticle/505

Lazari-Radek, K., \& Singer, P. (2014). The Point Of View Of The Universe - Sidgwick \& Contemporary Ethics. Oxford University Press. https://doi.org/10.1093/acprof:oso/9780199603695.001.0001

Martinelli, D., \& Berkmanienė, A. (2018). The Politics and the Demographics of Veganism: Notes for a Critical Analysis. International Journal on the Semiotics of Law, 31, 501. https://doi.org/10.1007/s11196-018-9543-3

McPhereson, T. (2018). The Ethical Basis for Veganism, in The Oxford Handbook of Food Ethics. 10: 210-240, Oxford University Press. https://doi.org/10.1093/oxfordhb/9780199372263.013.21

Napoli, P. M. (2014). Automated media: an institutional theory perspective on algorithmic media production and consumption. Communication Theory, 24(3), 340-360. https://doi.org/10.1111/comt.12039 
Pendergrast, N. (2016). Environmental Concerns and the Mainstreaming of Veganism. In T. Raphaely, \& D. Marinova (Eds.), Impact of Meat Consumption on Health and Environmental Sustainability (pp. 106-122). Hershey, PA: IGI Global. https://doi.org/10.4018/978-1-4666-9553-5.ch006

Roberts, J. A., Yaya, L. H. P., \& Manolis, C. (2014). The invisible addiction: Cell-phone activities and addiction among male and female college students. Journal of Behavioral Addictions, 3(4), 254-265. https://doi.org/10.1556/JBA.3.2014.015

Ruby, M. B., \& Heine, S. J. (2011). Meat, morals, and masculinity. Appetite, 56(2). https://doi.org/10.1016/j.appet.2011.01.018

Salih, S. (2014). Vegans on the verge of a nervous breakdown, in Taylor, N., Twine, R. (eds.) The Rise of Critical Animal Studies: From the Margins to the Centre, Routledge.

Schwartz, E. (2017). The Mystery of the Disappearing Avocado, Econlife, Available from https://econlife.com/2017/05/rising-avocado-prices/

Shiraev, E. (2010). A History of Psychology: A Global Perspective, Sage.

Singer, P. (1979). Practical Ethics, Cambridge University Press

Singer, P. (2000). A Darwinian Left, Yale University Press, New Haven.

Spencer, C. (1993). The Heretic's Feast. A History of Vegetarianism, London.

Steiner, C. (2012). Automate This: How Algorithms Came to Rule our World. New York: Penguin Books.

The Guardian (Fri 27 May, 2016). The rise of vegan teenagers: 'More people are into it because of Instagram', Available at:

https://www.theguardian.com/lifeandstyle/2016/may/27/the-rise-of-vegan-teenagers-more-people-are-into-it-becau se-of-instagram

Twine, R. (2014). Vegan Killjoys at the Table-Contesting Happiness and Negotiating Relationships with Food Practices, Societies, 4. https://doi.org/10.3390/soc4040623

Watson, D. (1944). Vegan Society Newsletter, Issue 1. November 1944, The Vegan Society.

Wescombe, N. J. (2019). Selznick, Schumacher, and Spinoza? Reframing the theory of communitarian liberalism for radical systems change, The Schumacher Institute, Working Paper, DOI: 10.13140/RG.2.2.21974.50242/1

Willett, W., Rockström, J., Loken, B., Springmann, M., Lang, T., Vermeulen, S., ... Murray, C. J. L. (2019). Food in the Anthropocene: the EAT-Lancet Commission on healthy diets from sustainable food systems, The Lancet, 393. https://doi.org/10.1016/S0140-6736(18)31788-4

\section{Copyrights}

Copyright for this article is retained by the author(s), with first publication rights granted to the journal.

This is an open-access article distributed under the terms and conditions of the Creative Commons Attribution license which permits unrestricted use, distribution, and reproduction in any medium, provided the original work is properly cited. 